\title{
LA REFORMA DE 1927 DE LA ANTIGUA UNIVERSIDAD DE OSUNA: UN CAMBIO RADICAL EN LA IMAGEN DEL EDIFICIO.
}

\author{
RAFAEL GONZÁLEZ DEL RÍO \\ Arquitecto
}

\section{Resumen}

La imagen actual del edificio de la antigua Universidad de Osuna es muy diferente de su concepción original del siglo XVI. Desde 1548 tanto el edificio como su entorno han sufrido profundas transformaciones, que convergen en un proceso histórico de aproximación consciente a un supuesto modelo teórico renacentista originario. Las obras de reforma llevadas a cabo en 1927 son un hito dentro de este proceso y han marcado la pauta de las intervenciones posteriores, contribuyendo decisivamente a su imagen actual: una "acrópolis ducal" con los edificios emblemáticos, exentos, organizados en una serie de plataformas y terrazas. Sin embargo, es más el resultado de criterios de restauración del siglo XIX y de elementos regionalistas.

\section{Palabras Clave}

IV Conde de Ureña. Urbanismo renacentista. Dictadura de Primo de Rivera. Francisco Rodríguez Marín. Pedro Sánchez Núñez, arquitecto. Siglo XX. Osuna, Sevilla, Andalucía, España. Reforma arquitectónica. Universidad.

\section{THE 1927 REFORM OF THE OLD UNIVERSITY OF OSUNA: A RADICAL CHANGE IN THE IMAGE OF THE BUILDING}

\section{Abstract}

The current image of the building of the old University of Osuna is very different from its original conception in the 16th century. Since 1548 both the building and its surroundings have changed, through a historical process of conscious approaching to the supposed original theoretical model of Renaissance. The renovation in 1927 is a milestone in this process and has set the reference for subsequent interventions, contributing to its current state: the "Ducal Acropolis", with isolated buildings arranged on platforms and terraces. However, it is more the result of restoration criteria in $19^{\text {th }}$ century and regionalist elements.

\section{Keywords}

4th Count of Ureña. Renaissance urbanism. Dictatorship of Primo de Rivera. Francisco Rodríguez Marín. Pedro Sánchez Núñez, architect. 20th century. Osuna, Seville, Andalusia, Spain. Architectural reform. University.

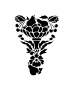




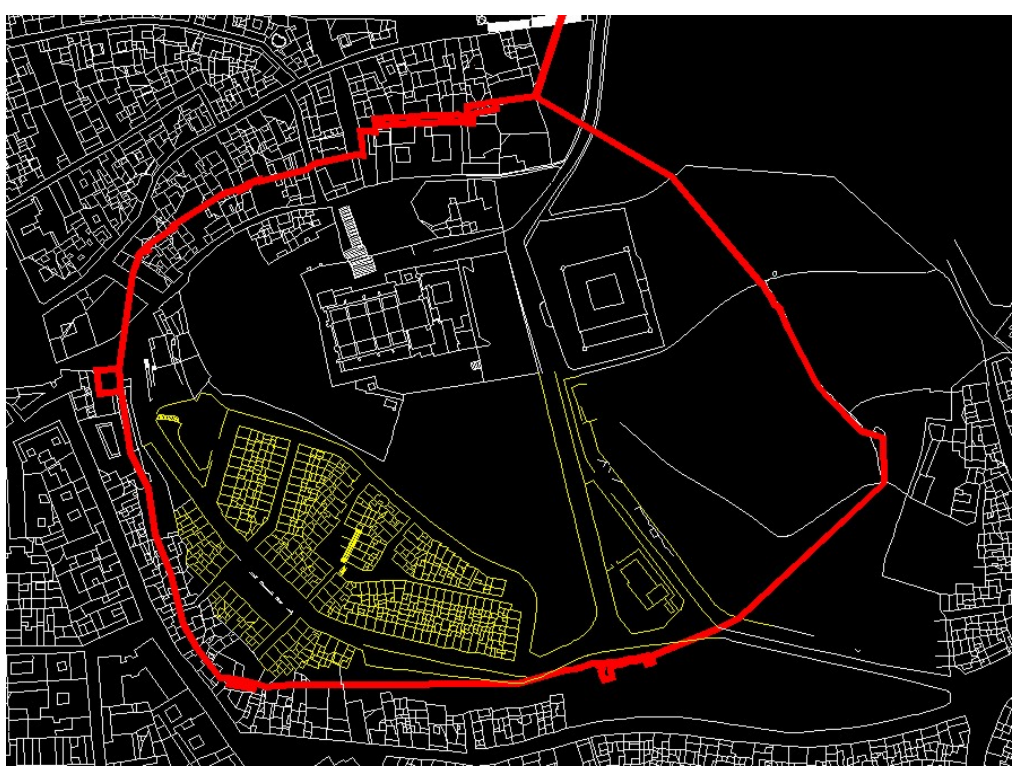

Fig.1. Hipótesis de recinto amurallado de Osuna. Finales del siglo XIX.

\section{La situación del edificio antes de las reformas de 1927}

No resulta fácil la reconstrucción ideal del entorno de la Universidad en el momento de su fundación. La primera pieza del puzle es el palacio-fortaleza, situado desde la época medieval en la zona más alta de la villa por razones defensivas. Como todos los alcázares se cerraba con otro muro hacia el interior de la ciudad, protegiéndose así tanto de los peligros exteriores como de las amenazas internas ${ }^{1}$. A finales del siglo XV, tras la guerra con el reino nazarí, cambió su función militar por la de residencia señorial. A mediados del XVI se separaba de la Colegiata mediante la Plaza de la Fortaleza, desde donde se accedía también a la Universidad por su fachada principal. Entre 1573 y 1580 se realizaron varias reformas de importancia, aunque en 1632 presentaba ya un estado de ruina irreversible, según un minucioso informe de los alarifes del concejo ${ }^{2}$. Debido a la falta de vigilancia se deterioró rápidamente y en la segunda mitad del XVII se abandona definitivamente. En 1746 García de Córdoba califica de ruinas el «suntuosísimo Palacio Viejo» y en 1829 Washington Irving se refiere a las «ruinas de un castillo», de las que hoy sólo son visibles los Paredones. Debió situarse al Sureste de la Universidad y las propias obras de 1927 debieron cambiar «radicalmente el entorno de toda la villa alta, desapareciendo una información que hubiera sido inestimable» ${ }^{3}$.

Otra incógnita a despejar es el grado de consolidación que presentaba el caserío medieval en la zona en el momento de erigirse la Universidad. Aunque no suelen ser realistas, los grabados históricos de Hoefnagle en 1560 o de Meissner en 1627, muestran la parte alta de la colina abigarrada de casas. Ya en 1531 el proceso de abandono de la villa alta estaba bastante avanzado, y no pudo frenarse con la instalación de la Universidad en el entorno de la Colegiata y el Palacio. La fundación del propio Seminario sería otro intento para paliar los efectos de este abandono. En el siglo XVIII «el despoblamiento es de tal magnitud que el

\footnotetext{
${ }^{1}$ Ledesma Gámez, F.: Las murallas de Osuna. Sevilla, Diputación de Sevilla, 2003, pág. 183 y ss.

2 Ledesma Gámez, F., ed.: Catálogo de la exposición: Del arca de las tres llaves al fichero digital. Quinientos años del Archivo de Osuna. Sevilla, 2009, pág. 154.

${ }^{3}$ Ledesma Gámez, F.: 2003, pág. 74 y ss.
} 


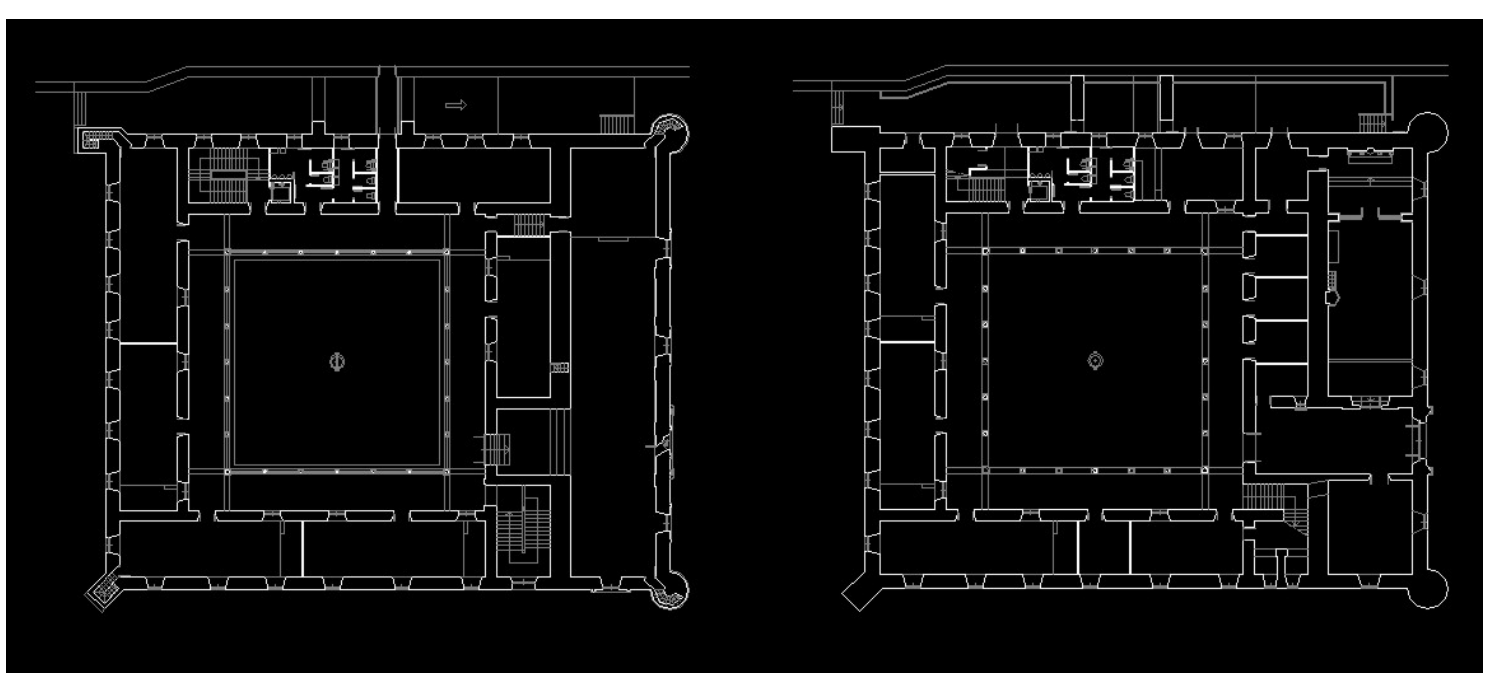

Fig. 2. Plantas baja y alta del estado actual del edificio.

espacio intramuros ha pasado a ser un erial» ${ }^{4}$. En la zona ya no se negocian casas sino fincas rústicas. El plano topográfico de la ciudad de 1895 refleja con claridad el resultado de este proceso.

Si observamos el plano actual con una hipótesis de trazado aproximado de la muralla (Figura 1), a finales del XIX dentro del antiguo recinto amurallado sólo quedarían en pie la Colegiata, la Universidad, la Encarnación, el Corral de la Sopa y el acceso desde la plaza Mayor a través de la cuesta de San Antón. La única operación urbanística posterior de reocupación del recinto abandonado ha sido la construcción, de la barriada de la Rehoya en los años 60, así como la apertura de la Cuesta de los Cipreses y el Paseo de la Universidad, ambos señalados en color amarillo.

En cualquier caso, sí sabemos que en 1548 el IV Conde de Ureña, funda el ColegioUniversidad de Osuna, en uno de los lados de la Plaza de la Fortaleza, derribando para ello varias casas de la zona en la calle del Castillo y en las cercanías de la Colegiata, cuyo templo estaba concluido en sus aspectos fundamentales en torno a $1540^{5}$. No está clara la relación de la Colegiata con la Plaza de la Fortaleza, a la que parece dar la espalda, y en la elección de su ubicación primaría la topografía como instrumento para plasmar a través del mismo el poder ducal sobre el entorno urbano y territorial, como puede observarse hoy en día.

La tradición exalta la figura del Conde como príncipe culto renacentista atribuyéndole la autoría de los planos del edificio de la Universidad y de las pinturas de la Girona. Aparte de la leyenda, su diseño estuvo influido por las nuevas ideas de la época, con modelos de recuperación de la cultura clásica procedentes de Italia. Como tipo de referencia para la implantación de edificios universitarios se utilizaba el palacio señorial ${ }^{6}$, como en la Antigua Universidad de Granada. Se prestaba especial atención a las dependencias representativas (la capilla y el salón de grados) y al patio central, alrededor del cual giraban las estancias. Quizás la Universidad de Osuna fuera para Don Juan el sucedáneo del palacio de nueva planta que nunca llegó a construir.

El análisis arquitectónico del edificio actual (Figura 2) muestra dos zonas perfectamente diferenciadas tanto desde el punto de vista espacial como constructivo. Poseen distinta altura,

\footnotetext{
${ }^{4}$ Ledesma Gámez, F.: 2003, pág. 58 y ss.

${ }^{5}$ Morales, A. J. y otros: Guía artística de Sevilla y su provincia. Sevilla, Diputación Provincial, 1989, pág. 474.

${ }^{6}$ Nieto, V. Morales, A.J. Checa, F.: Arquitectura del Renacimiento en España, 1488-1599. Madrid, Cátedra, 1989, pág. 230.
} 
volumetría, tipo de forjados, techos, tipo de huecos y en sus muros se diferencian los sillares de los tapiales.

a) La primera crujía, donde se ubican los elementos de mayor valor artístico e histórico y los menos modificados (la Girona, la Capilla y el Paraninfo) así como la fachada principal del edificio, con los dos torreones más emblemáticos.

b) El resto del edificio, con una simple crujía que gira alrededor del patio porticado de planta cuadrada. Es destacable que todas estas estancias se iluminan y ventilan desde el patio, por lo que las ventanas al exterior no son estrictamente necesarias, de modo que la existencia de edificaciones adosadas a esta crujía no afecta a su funcionalidad, como ocurre con el ala Sur y la de la fachada principal.

La segunda crujía participa de ambas zonas, con el vestíbulo como elemento de intersección. En ella se ubica la escalera, con una disposición algo forzada en planta en su salida al patio y el acceso al Paraninfo, que se sitúa justo encima del vestíbulo, en el que se resuelve la diferencia de altura con el resto de la planta alta. Esta diferencia se debe a que las estancias más representativas de la planta baja (Capilla, vestíbulo y Girona) tienen mayor altura de techo que el resto. El tejado de la segunda crujía es también algo más alto debido a la altura del techo del acceso al Paraninfo.

Estas diferencias entre las dos zonas nos inclinan a cuestionar la simultaneidad en su construcción, lo que significaría que la segunda, incluso el claustro, no sería original del XVI. En cualquier caso, sí tenemos la certeza de la existencia de los edificios adosados que se fundaron a los pocos años de la construcción de la Universidad. Por el Oeste, el ColegioConvento del Carmen en 1557, luego transformado en Colegio-Seminario del Corpus Christi (1608) y por el Norte, las Escuelas Menores de San Jerónimo, cuyas obras se desarrollaron desde 1559 a 1574 .

No existen demasiados datos sobre las posibles obras realizadas en el conjunto desde su fundación hasta la desaparición de la Universidad a principios del XIX. Sólo se han registrado ligeras reparaciones para su conservación y la habilitación de un cuarto rectoral en la planta alta. Esta falta de referencias ha llevado a suponer que el edificio no sufrió reformas de importancia. No obstante, en 1752 se encargaron a un maestro cantero de Estepa, 20 columnas y 4 extremos que, tanto por sus dimensiones (trece cuartas de alto), como por ser de orden dórico, deben ser las de planta baja ${ }^{8}$. Además, la solución de columnas dobles de las esquinas de esta planta es más propia del XVIII que del XVI ${ }^{9}$. De esta misma época parecen ser otras reformas, cuya importancia está por determinar, entre las cuales se incluiría una recomposición de la portada de la escalera ${ }^{10}$.

Según los datos disponibles sobre las obras realizadas en el edificio desde su cierre como Universidad hasta 1927, éstas fueron sólo de conservación y no afectaron demasiado a la configuración general del conjunto edificado. Antes de su cierre definitivo en $1824^{11}$, sufriría la ocupación de las tropas bonapartistas, que se concentraron en la zona alta de la villa entre 1810 y 1812, lo que pudo contribuir al deterioro del edificio y su entorno ${ }^{12}$.

\footnotetext{
7 Moreno de soto, P. y Ruiz cecilia, J.I.: "El Antiguo Edificio de la Universidad de Osuna y su complejo docente. Nuevas perspectivas". Cuadernos de los Amigos de los Museos de Osuna. No 9. Diciembre de 2007, pág. 46 y ss.

${ }^{8}$ Moreno de soto, P. y Ruiz cecilia, J.I.: Op. Cit. pág. 48. Reproducen parcialmente el documento existente en el Archivo Notarial de Estepa.

${ }^{9}$ Esta solución de semicolumnas con pilastra, al no repetirse en planta alta, origina que los arcos superiores situados junto a las esquinas sean ligeramente mayores que el resto, ya que no pueden coincidir los ejes de las columnas entre ambas plantas. La diferencia es de $20 \mathrm{~cm}$ y puede apreciarse a simple vista si se mira con atención.

${ }^{10}$ Moreno de soto, P. y Ruiz cecilia, J.I.:Op. Cit. pág. 46 y ss.

11 Mediante la Real Orden de 14 de octubre de 1824 se aprueba el Plan de Tadeo Calomarde (Plan literario de estudios y arreglo general de las Universidades del Reino) lo que supone el cierre definitivo de la Universidad de Osuna.

12 Según la tradición, la Universidad fue utilizada como cuartel por las tropas de Bonaparte y la Sala de Grados se usó como cuerpo de guardia, donde era habitual encender hogueras, lo que ocasionó graves daños a las pinturas.
} 


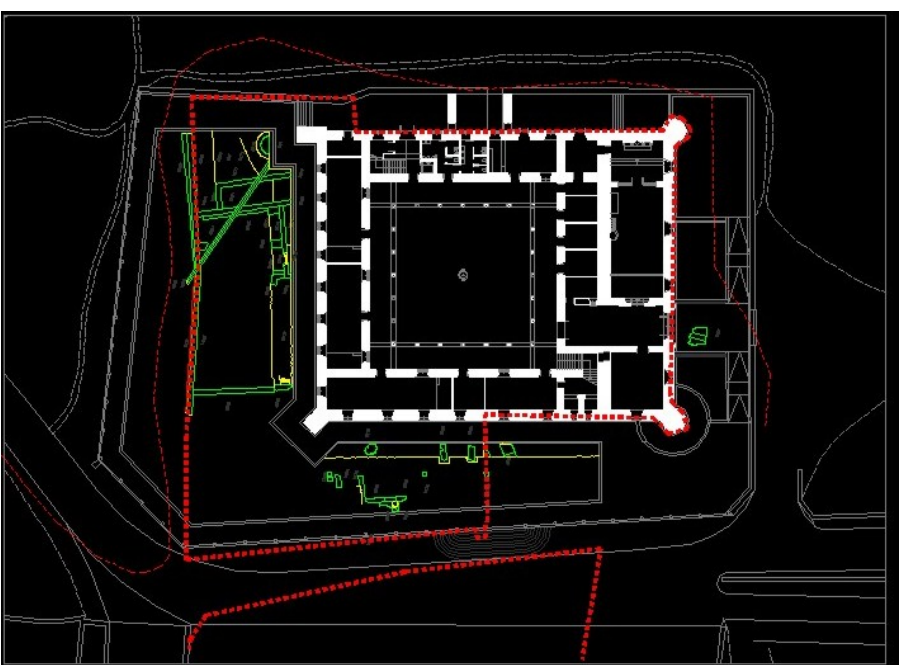

Fig. 3. El edificio actual y su entorno. En rojo, el límite edificatorio según plano de Osuna de 1896. En verde, los restos arqueológicos estudiados.

La Junta Creadora del Instituto de Segunda Enseñanza, realizaría algunas reparaciones en el mismo, antes de su apertura en 1847. Debido a la escasez de medios que contó el Instituto hasta su cierre en 1876, el edificio debió sufrir un deterioro apreciable. En una inspección realizada en 1875, una de las razones que se aducen para proponer su cierre es el inminente estado de ruina en que se hallaba. No obstante el Ayuntamiento solicitaría la revocación del Decreto de suspensión del Instituto, acompañando un plano y dibujos del edificio y un informe técnico, que señalaría que se encontraba en perfecto estado de solidez. ${ }^{13}$

En 1879 se abriría en el edificio un Colegio de Segunda Enseñanza adscrito al Instituto de Sevilla que mantuvo la denominación del anterior: "La Purísima Concepción". Para su apertura el Ayuntamiento tuvo que acometer obras de reparación de algunas de las columnas del patio, que estaban partidas y amenazaban la ruina del claustro en planta alta, por lo que no estaría muy desacertado el informe de 1875. El Colegio, que incluía un internado, fue gestionado por el último director del Instituto, Enrique Rodríguez Durán y cerraría cuando éste se marcha de Osuna en 1904.

En 1906 se abrió un nuevo Colegio de Segunda Enseñanza, con el mismo nombre, gestionado por Bonifacio Obispo Román, dependiendo del Instituto General y Técnico de Sevilla. En la solicitud realizada al Ayuntamiento por el sacerdote palentino se especifica que una Comisión determinaría las obras que debían realizarse en el edificio antes de su apertura ${ }^{14}$, de donde puede suponerse que se realizaron más obras. Con ocasión de la modificación del contrato en 1917, se realizarían también obras de reparación del tejado en la parte norte ${ }^{15}$, que podrían haber afectado a la zona de las antiguas Escuelas Menores. Este Colegio funcionaría hasta la reinstauración del Instituto en 1927.

Así pues, en 1927 nos encontramos con un complejo de edificios bastante más amplio que el actual, con el Seminario del Corpus Christi adosado por el Oeste y las Escuelas Menores por el Norte. Estaba aislado del resto de la población, en un entorno rústico y con un único acceso urbano por la empinada y estrecha cuesta de San Antón. Para llegar a la Universidad habría que rodear las tapias del antiguo cementerio de la Colegiata, por el callejón de los Seminarios y atravesar el arquillo del mismo, desde donde se accedería a una ligera explanada delante de la fachada principal ${ }^{16}$. Poseía una puerta trasera abierta en las Escuelas Menores, que enlazaría con el camino rústico de Buenavista. El estado general del edificio dejaría bastante que desear, sobre todo por la falta de mantenimiento. Desde su decadencia tras el cierre de la Universidad hacía algo más de un siglo, y tras el período de penuria 578.

${ }^{13}$ Ramírez Olid, J.M.: Osuna durante la restauración (1875-1931). Osuna, Ayuntamiento de Osuna, 1999, pág.

${ }^{14}$ Archivo Municipal de Osuna (A.M.O.) Acta capitular 6/10/1905, folio 79.

15 A.M.O. Acta capitular 15/06/1917, folio 15.

16 Del castillo no debía quedar mucho más que los actuales Paredones. 
económica del primer Instituto de Segunda Enseñanza, no parece que el Ayuntamiento hubiera realizado demasiadas obras de conservación en los dos períodos del Colegio de la Purísima Concepción. No obstante, estaba en funcionamiento el Colegio de Bonifacio Obispo y, posiblemente, este uso casi continuado desde 1847 lo habría salvado de la ruina.

\section{La dictadura de Primo de Rivera y la recuperación del Instituto en Osuna}

En septiembre de 1923 accede al poder en España el General Primo de Rivera instaurando una Dictadura que, bajo el reinado de Alfonso XIII, se prolongaría hasta principios de 1930. En este período de menos de siete años se sucedieron en Osuna varias iniciativas que redundarían en una mejora de las condiciones de vida de los ciudadanos, dentro siempre de un clima generalizado de prácticas caciquiles y bajo la corrupción política imperante. Entre estas iniciativas se incluyen el estudio de una posible solución del endémico problema de falta de agua potable, encargándose un proyecto al ingeniero Eduardo Torroja y Miret ${ }^{17}$, la pavimentación de muchas calles, las reformas en las escuelas públicas, ampliaciones de la red de alumbrado y del matadero o la construcción del cuartel de la Guardia Civil. También las obras de reforma en la antigua Universidad para la instalación del Instituto Nacional de Segunda Enseñanza.

En la decisión de la creación del Instituto fueron determinantes las influencias ejercidas por dos personajes antagónicos, por su carácter, por su posición y por su ideología. El primero, Antonio Tamayo Contreras, marqués de la Gomera, miembro de la Asamblea Nacional y amigo del dictador. Suya fue la idea de solicitar la recuperación del instituto de bachillerato en Osuna, donde era el principal contribuyente y hombre fuerte. La Corporación de la época estaba hecha a su medida, con su sobrino, Antonio de Castro Tamayo, como Alcalde. En la propia Memoria del Proyecto aparece una referencia a que fue el artífice de la recuperación del Instituto, lo que nos hace pensar que pudo tener alguna intervención en la elección del arquitecto.

El segundo personaje clave fue Francisco Rodríguez Marín, Director de la Biblioteca Nacional, ex alumno del Instituto, y miembro del consejo de Instrucción Pública que debía impulsar su recuperación. Sería su gran valedor, de manera que el Instituto lleva aún su nombre y sus restos se encuentran depositados en el Oratorio ${ }^{18}$.

Tal y como señala Ramírez Olid ${ }^{15}$ los hechos se suceden con una inusitada celeridad. Transcurren sólo tres meses desde la solicitud municipal hasta que se aprueba su instauración. El 22 de abril de 1927 el Pleno Municipal solicita la creación del Instituto comprometiéndose a ceder el edificio (del que se acompaña un plano y croquis) y a acometer obras de reforma, mejora y adaptación por cuenta del Ayuntamiento. El 21 de junio se reúne el Consejo de Instrucción Pública del que forma parte Rodríguez Marín y se informa favorablemente, por lo que el Consejo de Ministros aprueba el 23 de julio la creación del Instituto. En el diario ABC del 27 de julio se da cuenta de las muestras de agradecimiento recibidas en el Ministerio de Instrucción pública ${ }^{20}$.

En el Pleno extraordinario celebrado el 1 de agosto ${ }^{21}$, se recuerda que el Ayuntamiento debe acometer de manera inmediata obras de adecuación del edificio, pavimentación de las

17 Ramírez Olid, J.M.: 1999, pág. 678.

18 En una placa situada en el vestíbulo se conmemora: «Durante el reinado de S.M. Don Alfonso XIII, siendo Presidente del Consejo de Ministros el Excmo. Sr. D. Miguel Primo de Rivera Marqués de Estella, Alcalde de esa Villa D. Antonio de Castro Tamayo, se reedificó este edificio que fue Universidad de brillante historia, para instalar el nuevo Instituto Nacional de $2^{a}$ Enseñanza concedido por el Gobierno de S.M. y por gestión de los hijos de esta localidad D. Antonio Tamayo Contreras, Marqués de la Gomera, Asambleísta Nacional, Excmo. Sr. D. Francisco Rodríguez Marín, Director de la Biblioteca Nacional, y Excmo. Sr. D. Ricardo Contreras Montes, Teniente General. Dio comienzo la labor docente de este centro el día $1^{\circ}$ de Octubre de 1927. Dirigió las obras el arquitecto D. Pedro Sánchez Núñez. Terminaron en 1928».

${ }^{19}$ Ramírez Olid, J.M.: 1999, pág. 589.

${ }^{20}$ Diario ABC de 27/07/1927, pág. 15.

21 A.M.O. Acta de Plenos 1/8/1927, folios 85-91. 


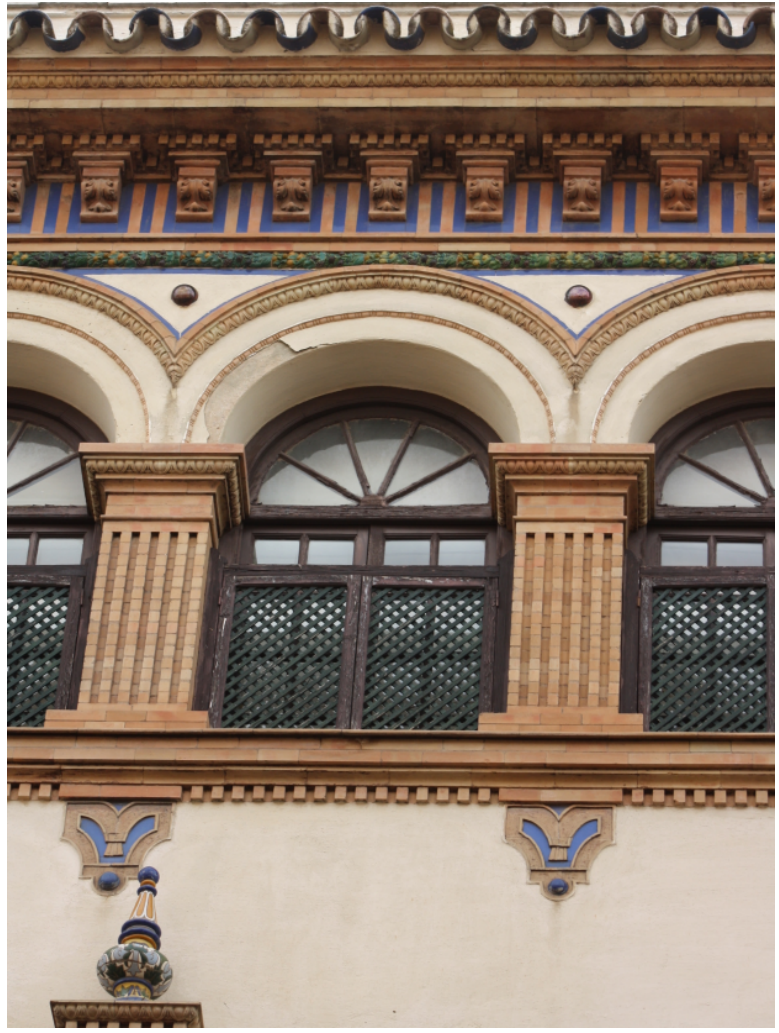

Fig. 4. Casa propia del arquitecto Pedro Sánchez Núñez. Calle Matahacas 39 (Sevilla). 192223. Por menor de la fachada.

vías públicas por las que se accede al mismo y adecentamiento del entorno ya que el Centro ha de comenzar a funcionar el 1 de octubre, sólo dos meses después. Se decide:

... dar inmediato encargo a un Sr. Arquitecto de la Capital, por no haberlo municipal, ni existir en la población técnicos de dicha profesión, ... para que... formule un proyecto de las reformas que, en consonancia con las indicaciones del Sr. Alcalde, puedan realizarse.

Asimismo, se determina que:

... con vista del proyecto o presupuesto que formule el Sr. Arquitecto, a base de las reformas que la Comisión Permanente juzgue necesarias, se proceda por el Maestro titular de Obras a formar un proyecto y presupuesto de las que deban realizarse para la decorosa instalación del Instituto, de urbanización de los contornos del edificio y de pavimentación de la calle o calles que dan acceso al mismo.

El 10 de agosto se reúne el Pleno del Ayuntamiento para determinar el sistema de financiación de las obras. Los gastos se afrontarán mediante la suscripción de un crédito con el Banco de España. El Ayuntamiento puede asumirlo gracias al Estatuto Municipal de Calvo Sotelo de 1924, que supuso una sensible mejora en la capacidad de gasto municipal y permitiría financiar ésta y el resto de obras públicas reseñadas.

El Real Decreto se publica el 18 de agosto en la Gaceta de Madrid. En el artículo $6^{\circ}$ del mismo se señala que el Ayuntamiento hará entrega del edificio al representante del Ministerio de Instrucción Pública y Bellas Artes, previo reconocimiento por el arquitecto del Ministerio de la provincia y una Comisión de Catedráticos del Instituto de Sevilla. También deberá encargarse de realizar por su cuenta las modificaciones y reformas que requieran las exigencias pedagógicas o higiénicas, a propuesta de la inspección del Ministerio. Además, el Ayuntamiento deberá adquirir y entregar al Instituto un solar para campo de deportes donde los alumnos puedan realizar los ejercicios físicos obligatorios en el nuevo plan de estudios del Bachillerato. 


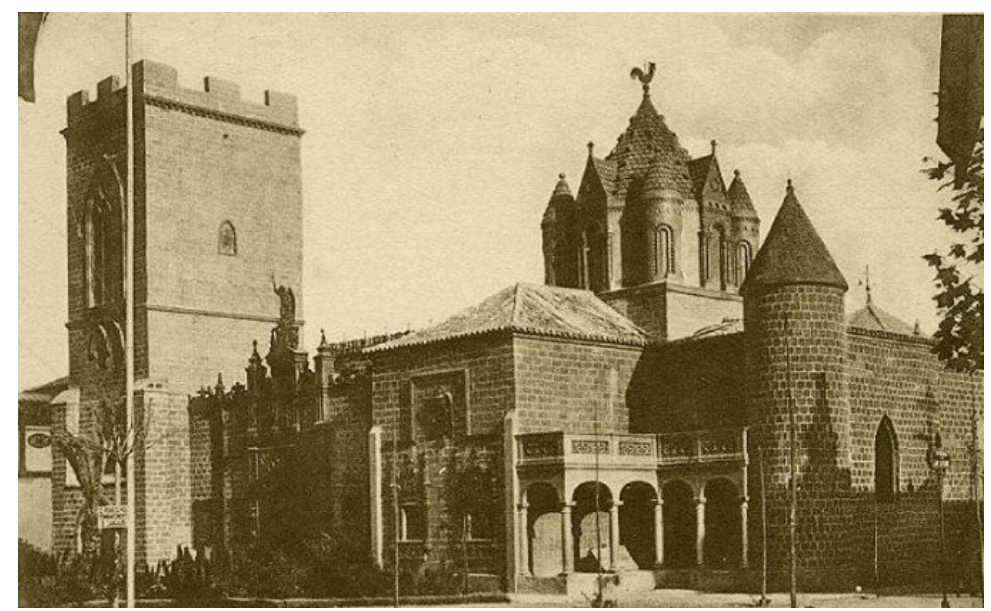

Fig. 5. Pabellón de Castilla la Vieja y León. Exposición Iberoamericana de 1929.

\section{$\mathrm{El}$ arquitecto y su contexto}

El proyecto se encarga al arquitecto Pedro Sánchez Núñez (1882-1956) ${ }^{22}$. Colegiado en 1916 y con estudio profesional en Sevilla, tuvo cierta relevancia dentro del regionalismo de la época. Movellán lo encuadra dentro de la que llama generación de 1917, junto a arquitectos como Antonio Illanes y Juan José López Sáez.

En 1916, recién titulado, redacta un proyecto para la Plaza de Toros de Cádiz y presenta una propuesta neomudéjar al concurso del Hotel Alfonso XIII. Posteriormente cambia de tendencia, integrándose a la corriente neobarroca propugnada por Vicente Traver y seguida, entre otros, por José Espiau, Antonio Gómez Millán y Ramón Balbuena. Tras un periodo como arquitecto del Catastro, en 1917 ejerce de Secretario, como representante más joven, del IV Congreso Nacional de Arquitectos, que supuso la exaltación de Aníbal González y el espaldarazo definitivo al regionalismo sevillano. Este estilo se desarrollará durante el periodo de auge del sector de la construcción en la Dictadura de Primo de Rivera, cuyo reflejo será la Exposición Iberoamericana de 1929 de Sevilla. Veamos ahora en detalle algunas de sus obras y proyectos en Sevilla.

La casa Artemán, situada en la Avenida Miraflores, 21 (1918-20) posee una ornamentación neobarroca con filetes de ladrillo que pueden recordar a Talavera y Arévalo, y elementos lineales como las volutas, para reafirmar el dibujo superpuesto a la fachada. Se utilizan guirnaldas de cerámica vidriada y motivos de fuerte contraste como el frontón mixtilíneo de coronación. El edificio para viviendas para Manuel Campos Peña, situado en el Paseo de Colón 12-14 (1921-24) sería una de sus obras más ambiciosas. El promotor era un consignatario de buques que había hecho fortuna con el avituallamiento del ejército de Marruecos. Posee cuatro accesos y simetrías axiales. Con un estilo muy personal, síntesis entre el barroco y el mudéjar, ofrece interesantes juegos de volúmenes, materiales y colores.

La obra más interesante de esta época (Figura 4) es su propia casa en la calle Matahacas, 39 (1922-23) que luego vendería a la Viuda de Cubas. Muestra una fachada muy equilibrada coronada por una galería de arcos sobre pilastras acanaladas y un grueso frontón sobre el balcón de la portada. En la casa de viviendas en la calle Zaragoza, 48 (1925) también de gran interés, todavía mantiene reminiscencias neomudéjares y neobarrocas, mezclando los dos estilos de manera ecléctica.

22 Villar Movellán, A.: Arquitectura del Regionalismo en Sevilla (1900-1935). Sevilla, Diputación de Sevilla, 1979. Todas las referencias sobre Pedro Sánchez Núñez se han obtenido de este exhaustivo trabajo sobre este movimiento arquitectónico. 
Fig. 6. Proyecto de obras de 1927. Portada.

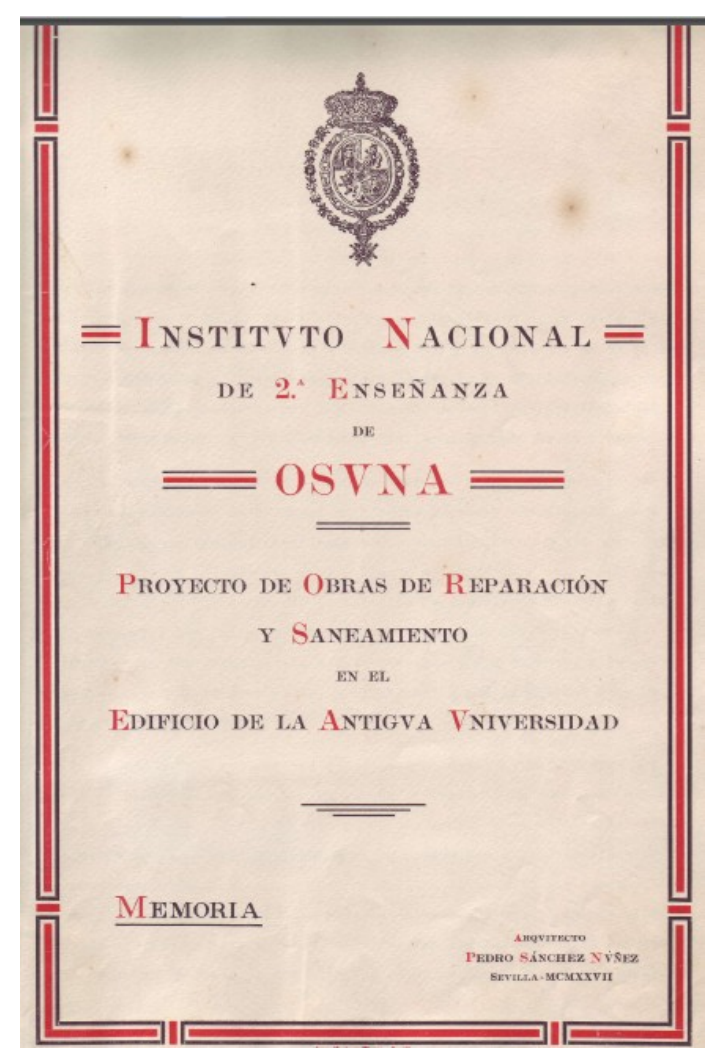

Junto al arquitecto Ricardo Magdalena, en 1926 participa en el concurso para el nuevo Mercado de la Puerta de la Carne, presentando una propuesta con aires neobarrocos. Destaca la gran portada y dos torres meramente decorativas. El proyecto ganador del concurso sería finalmente el de Gabriel Lupiáñez y Aurelio Gómez Millán, convirtiéndose en una de las primeras obras del racionalismo en Sevilla.

A partir de 1925 participa en varias obras de la Exposición Iberoamericana. Tras la dimisión de Aníbal González, se hace cargo de la conclusión de las obras de la Plaza de España. En 1927 realiza el acondicionamiento de los Jardines de San Telmo. En 1928 trabaja en la ordenación de la Exposición Ganadera, en varios proyectos para el Campo de Polo y en reformas para el hipódromo de Tablada.

En el mismo año 1928 construye el Pabellón de Castilla la Vieja y León, donde reproduce literalmente elementos de las Murallas de Ávila, la Torre de San Miguel de Palencia, el Hospital del Rey de Burgos, etc. El proyecto encaja dentro de una corriente "proturística" que originaría el Pueblo Español de Barcelona (Figura 5).

En los años posteriores a la exposición del 29 mostraría un creciente interés por la "arquitectura blanca", como el resto de arquitectos de la Generación del 17. Esta tendencia de reducción de la ornamentación, promovida por Talavera, se basaba en la arquitectura rural y fue el origen del gusto por un supuesto estilo andaluz que ha llegado hasta nuestra época. En las viviendas y almacén para Manuel Campos Peña, en la Calle Rodo 14, esquina a General Castaños 25 (1930-31) se definen con precisión el basamento de ladrillo y los pisos encalados sobre los que destaca el ático.

En 1930, junto al arquitecto Saturnino Ulargui y al ingeniero de minas Eduardo Carvajal, redacta un plan de Ensanche de Sevilla, que incluía un crecimiento exterior de la ciudad y diversas actuaciones para ensanches interiores. Algunos de éstos se hicieron en los años 5060 y alguno más, como el del barrio de Santa Cruz, afortunadamente nunca se llevaría a cabo. La filosofía de estos ensanches suponía la apertura de nuevos ejes viarios dentro del casco histórico para facilitar la circulación y los accesos, derribando el caserío tradicional.

Así pues, durante el periodo en que Pedro Sánchez Núñez trabaja en la Universidad de Osuna (de septiembre de 1927 a agosto de 1928) debía encontrarse bastante ocupado. Tenía 
que simultanear el proyecto y dirección de las obras con varios encargos de importancia en la Exposición Iberoamericana, que se inauguraría en mayo de 1929. Sobre todo, la terminación de las obras de la Plaza de España, de las que fue responsable desde septiembre de 1926 hasta su finalización en 1928.

\section{Análisis del proyecto de 1927}

\section{La Memoria}

En el Archivo Municipal de Osuna se conservan la Memoria y el Presupuesto del proyecto de $1927^{23}$. No ha aparecido ningún plano, aunque debieron existir, ya que se hace referencia a ellos en la Memoria. La consulta de los mismos hubiera podido ser útil para conocer las trazas de las construcciones anexas demolidas, aunque quizás no debieran ser demasiado precisos, por el nivel de detalle habitual en los planos de la época, por la premura de tiempo con la que se redactó y por tratarse de zonas a demoler. Las prisas en la redacción del proyecto se reconocen en la propia Memoria:

Una vez aprobado el presente presupuesto y plan de obras, será el momento oportuno de redactar los pliegos de condiciones de las diferentes clases de obras, tanto facultativas como económicas, así como las Memorias correspondientes a las mismas, que por apremios de tiempo y no ser necesarias de momento no se acompañan.

Tampoco hemos creido necesario incluir los cuadros de precios de jornales y materiales, ni su detalle o descomposición puesto que según se nos ha manifestado es propósito del Excmo. Ayuntamiento ejecutar las obras por el sistema de administración o bien por destajos parciales.

El proyecto debió redactarse en menos de un mes, ya que al parecer a primeros de septiembre ya se estaba trabajando en él ${ }^{24}$ y la Memoria aparece fechada el 30 del mismo mes. El 3 de noviembre se inician las obras, que se simultanean con las clases, ya que el curso había comenzado previamente el 1 de octubre. Estaban terminadas en agosto de 1928.

Como se señala en la Memoria fueron ejecutadas por el propio Ayuntamiento por el sistema de administración, no participando empresa constructora alguna. Al frente de las mismas debió estar el Maestro titular de Obras a que se hacía referencia en el acuerdo de Pleno de 1 de agosto.

De la lectura de los documentos disponibles de proyecto sólo pueden deducirse las previsiones del mismo, no las obras realmente ejecutadas. Las desviaciones son habituales en cualquier tipo de obras y en especial, en una como ésta, donde el proyecto se había redactado con cierta precipitación.

El presupuesto puede desglosarse en los siguientes capítulos: solerías $(27,80 \%)$, zócalos $(10,94 \%)$, alicatados $(4,46 \%)$, albañilería $(5,76 \%)$, herrajes $(4,26 \%)$, carpintería $(20,22 \%)$, yeserías $(1,69 \%)$, pinturas $(5,57 \%)$ e instalaciones $(19,30 \%)$. Como puede observarse, las partidas más importantes son las de solería, carpintería e instalaciones. Ascendió a la cifra total de 210.098,59 pesetas, incluyéndose en dicha cantidad porcentajes para los imprevistos, retiro obrero y accidentes de trabajo, así como para los honorarios de proyecto, dirección y administración de las obras. Considerando las características de un Ayuntamiento de esa época, esta inversión debió suponer un importante esfuerzo para las arcas municipales.

Derribo de edificios adosados

Respecto a su contenido y objetivos, es muy ilustrativa la lectura de la Memoria: El edificio, erigido en el año de 1549 por D. Juan Téllez-Girón, IV Conde de Ureña, señor de Osuna, es un hermoso y sobrio ejemplar del Arte del Renacimiento Español cuya traza y distribución, según puede apreciarse en los planos adjuntos, es perfectamente adecuada para un centro docente, siendo unicamente necesario al instalar de nuevo en su recinto el Instituto, reparar los daños que el tiempo y el 202.

${ }^{23}$ A.M.O. Obras y Urbanismo. Planos y Proyectos. Proyecto de Reforma del Instituto (1927-1952) Sig.

${ }^{24}$ Ramírez Olid, J.M.: 1999, pág. 591. 


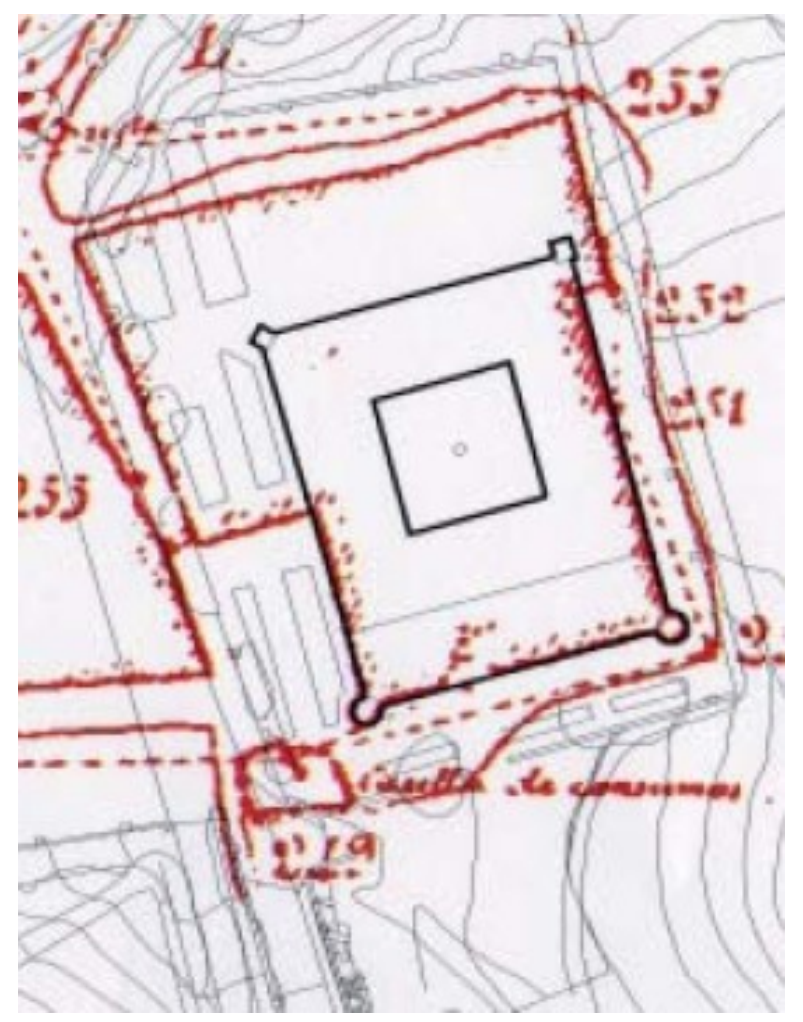

Fig.7. Superposición del plano de Osuna de 1896 con la planimetría actual.

mal uso han ocasionado, así como abrir en sus fachadas los huecos precisos a fin de dotar a los locales destinados a Cátedras de la luzy aireación que la Higiene y la Pedagogía modernas exigen.

Asípues las obras que se proponen y detallan en el adjunto Proyecto y Presupuesto, se reducen en líneas generales a la apertura de dichos huecos o ventanas, previa demolición de las construcciones adosadas al edificio, que sobre no ser utilizables en su estado actual, restan visualidad al conjunto y afean su severa y caracteristica silueta.

Por tanto, en la fachada Oeste se derriba el Seminario y en la fachada Norte las Escuelas Menores. Visualmente, considera que el edificio es lo que hoy queda de él, sólo las crujías que rodean el patio. El resto son sólo «construcciones adosadas» que afean el conjunto y su silueta.

Respecto al estado ruinoso de las construcciones adosadas, según Francisco Olid ${ }^{25}$, en la fachada norte Don Bonifacio tenía unos corrales donde criaba conejos y gallinas, lo que puede hacer suponer que esa zona ya estaba en ruinas. A la misma conclusión puede llegarse tras constatar que, durante las excavaciones de 2002, aparecieron acumulaciones de basuras en el mismo sector ${ }^{26}$.

En cuanto al presupuesto, no se valoran las obras de demolición, por lo que tampoco disponemos de una descripción de las obras de derribo realizadas. Según la Memoria:

... no se incluye cantidad alguna por las demoliciones que hayan de efectuarse por suponer que su costo estará compensado con el valor del aprovechamiento de los materiales resultantes del derribo.

En fotos de la zona de principios del siglo XX pueden adivinarse algunas características de las edificaciones demolidas. El Colegio-Seminario tenía una planta de altura, poseía una espadaña y se relacionaba con la tapia del cementerio mediante un arquillo que se apoyaba en ambos, sobre el callejón de los Seminarios. El arquillo estaría alineado con la fachada del

${ }^{25}$ Ramírez Olid, J.M.: “La enseñanza secundaria en Osuna 1847-1927” en Hijo de entendimiento. Homenaje a don Alfredo Malo, catedrático en Osuna. Osuna, Ayuntamiento de Osuna, 1992. Basándose en una conferencia de 1978 de Francisco Olid Maysounave. Pág. 183.

26 Moreno de Soto, P. y Ruíz Cecilia, J.I.: 2007, pág. 53. 


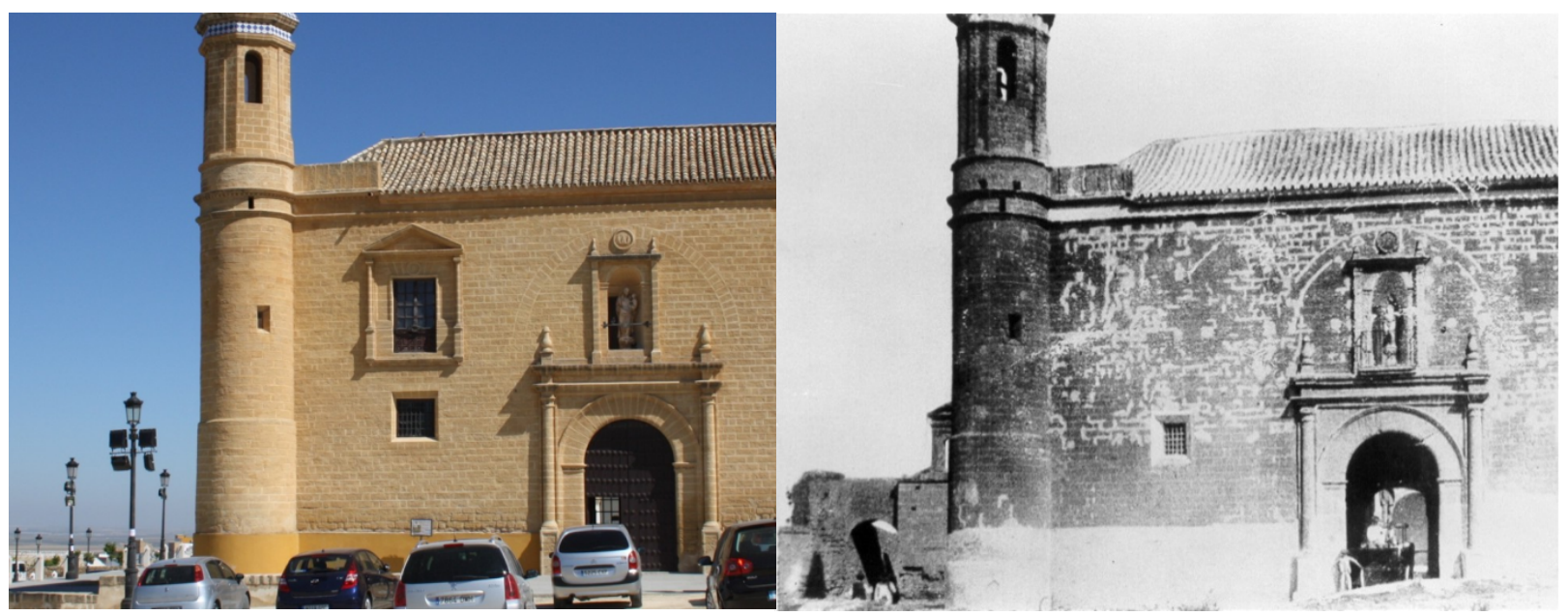

Fig. 8. Fotografía de comienzos de siglo. Puede apreciarse la fachada de las Escuelas Menores (a la izquierda) y la ventana añadida, así como la campana en el torreón.

Corpus Christi, y se situaría justo en el eje de la actual escalinata que da acceso a la plataforma. Las Escuelas Menores tenía un volumen de mayor altura que el Seminario, y su cubierta de tejas parece continuar el faldón de la Universidad. Se observa una salida falsa desde el patio trasero al campo.

En la fachada Oeste en planta alta se intuyen unas pequeñas ventanas que corresponderían a las camarillas o aposentos de los colegiales, que según Francisco Olid se suprimieron también con las obras del $27^{27}$.

\section{La plataforma y su escalinata}

De los escombros procedentes del derribo de las dos edificaciones adosadas surge la plataforma donde se asienta actualmente la Universidad, tal y como se constató en las excavaciones de 2002. En la superposición con el plano de $1895^{28}$ puede observarse como el quiebro del muro que delimita el foso en su extremo norte se correspondería con la fachada de las Escuelas Menores (figura 7 ) $^{29}$.

Aunque no aparece referencia a la plataforma en el proyecto, su situación se corresponde precisamente con los dos cuerpos demolidos (al norte y al oeste), con una zona ampliada al Norte de unos $500 \mathrm{~m}^{2}$, más el enlace con la fachada principal. ${ }^{30}$

La necesidad de crear un campo de deportes en la zona norte, obligaría a explanar el terreno para conseguir una superficie llana, más elevada que la cota del callejón de los Seminarios, que se extendería alrededor del edificio principal. Surge así la plataforma, a modo de basamento o peana de la Universidad, con una función similar al atrio situado junto a la Torre de la Colegiata grafiado en el plano de $1895^{31}$. Las zonas sur y oeste de la plataforma se pavimentarían en 1978, siendo la zona norte terriza la conocida más tarde como el campo de tenis.

${ }^{27}$ En la Memoria de la propuesta de ampliación de 1982, se dice también que se eliminaron «las llamadas "camarillas" o aposentos de los colegiales mayores de la antigua Universidad, que situadas bajo la cubierta y con pequeñas ventanas al exterior configuraban en cierta medida la edificación».

28 Moreno de Soto, P. y Ruíz Celcilia, J.I.: 2007, pág. 54.

${ }^{29}$ Moreno de Soto, P. y Ruíz Cecilia J.I.: Op. Cit. pág. 54.

${ }^{30}$ Para las actuaciones en el entorno se dispuso además de una parcela de una fanega de tierra cedida por Carmen Pulido Alés, colindante con el edificio por dos de sus lados, aunque no sabemos exactamente dónde se situaba.

${ }^{31}$ La terraza situada junto a la Puerta del Sol de la Colegiata también se ampliaría después de 1895. 
La escalinata que se sitúa en la zona Oeste de la plataforma debe ser esta misma época, si nos atenemos a las características de la baldosa hidráulica con la que está solada. Con una situación un tanto forzada, resuelve funcionalmente la comunicación peatonal entre plataforma y explanada, mostrando la difícil relación existente entre la Universidad y la Colegiata. La ubicación de la escalinata, casi centrada con el patio, parece demandar la existencia de una portada en la fachada lateral de la Universidad, que al parecer llegó a buscarse en algún momento. Pero esta idea debe desecharse a la vista de la evolución histórica de los edificios y su entorno: se trata de un añadido de 1927 que nada tiene que ver con la configuración original de la Universidad y su entorno.

Las nuevas fachadas

En la Memoria se señala como uno de los objetivos principales de la intervención el de «abrir en sus fachadas los huecos precisos a fin de dotar a los locales destinados a Cátedras de la luz y aireación que la Higiene y la Pedagogía modernas exigen». La apertura de dichos huecos se hacía precisa, no tanto por razones higiénicas para la iluminación y ventilación de las estancias que, como se ha señalado anteriormente, no sería estrictamente necesaria, sino más bien para resolver las nuevas fachadas que el inmueble ofrecía tras la demolición de las construcciones adosadas. ${ }^{32}$

En relación con las nuevas ventanas, se prevén en el presupuesto casi $110 \mathrm{~m}^{3}$ de apertura de huecos en cantería. Teniendo en cuenta el tamaño actual de los mismos, significaría la apertura de cerca de 40 ventanas, correspondientes a las tres fachadas secundarias, además de algún vano nuevo en el claustro que pudiera ser necesario por cambios en la distribución. En las mediciones aparecen 26 dinteles de hierro laminado, destinados a estos nuevos huecos. A todas las nuevas ventanas se las dotó «de sus correspondientes rejas de hierro, análogas a las de sencillo trazado que aún subsisten en otros vanos. En el presupuesto aparecen $58 \mathrm{~m}^{2}$ de rejas voladas de hierro dulce», superficie que se corresponde aproximadamente con los 26 dinteles anteriormente reseñados.

Así pues, estas tres fachadas surgen como hoy las conocemos a partir de las obras de 1927, cuando se suprimen las construcciones adosadas y se abren las nuevas ventanas. De hecho la disposición regular de las mismas no se corresponde con las asimetrías de la fachada original, y respondería quizás a la voluntad de proponer una trama neutra donde se diferenciaran los huecos añadidos de los primitivos. Ahora bien, esta trama se corresponde más con el ideal renacentista que la propia fachada principal, si no en la utilización de los órdenes en el diseño de huecos, al menos en la disposición de los mismos. En cualquier caso, es la imagen que nos ha quedado del edificio, con su supuesta sobriedad renacentista.

En la fachada principal se abrió un nuevo balcón en la planta alta sobre la Girona, reproduciendo el diseño de los existentes, y con una cierta voluntad de completar el proyecto original (Figura 8). Puede observarse que este hueco no existe en las fotos de principios de siglo. De hecho, es el único a eje con los inferiores. Siempre ha llamado la atención en una fachada del XVI como ésta, tanto este descentramiento de huecos, como la asimetría en la ubicación de la portada.

Comparando las fotos antiguas con las actuales pueden apreciarse también unos restos de saeteras en la fachada del Oratorio ${ }^{33}$, una campana situada sobre el torreón y unos pequeños huecos hoy tapiados en el mismo. También, que la ventana de la Girona era algo más estrecha que la actual, quizás por haberse igualado con las de la capilla, con el criterio adoptado en el 27 de homogeneizar huecos dispares.

Apertura del foso

Uno de los elementos característicos de la Universidad es el foso que la separa del terreno en su fachada Este. En el plano urbano de 1895 aparece una cierta zona de circulación por

32 Esto significa que las nuevas fachadas son consecuencia de la apertura de huecos pero, también, viceversa, se abren las nuevas ventanas con el fin de configurar unas nuevas fachadas.

33 Moreno de Soto, P. y Ruíz Cecilia, J.I.: 2007, pág. 51. 
ese lado de la edificación, que llega a rodear las Escuelas Menores. Antes de su existencia, y si el terreno colindante estaba a la cota actual, las estancias de la planta baja del ala Este debían estar bajo rasante.

El foso debió abrirse en este momento, asociado al acceso al recién creado campo de juego $^{34}$. Dentro del objetivo general de mejorar la iluminación y aireación de las estancias, permite la apertura de nuevos huecos en la planta baja del ala norte. Si las obras se realizaron en el 27, debieron suponer unos gastos importantes que no aparecen reflejados ni en el Presupuesto ni en la Memoria. Nos quedaría por tanto un margen de incertidumbre sobre si el foso procede de esa época.

Según Burraco y Barrera ${ }^{35}$, su apertura originaría en toda esta zona problemas estructurales, quizás por el empuje de las cubiertas. Esto obligaría en 1949 a añadir los dos contrafuertes, según proyecto de José Granados, y con una factura similar a los de la Plaza de Toros. Estos arquitectos señalan que en 1967, también en la zona Este, se desmonta y reconstruye la arquería de planta alta. Todos estos problemas estructurales se solucionarían cuando se sustituyeron las cubiertas de esa nave, suprimiéndose los empujes laterales en los muros.

Revestimientos de fachadas

Continuando con las fachadas, otra partida importante fue el revestimiento de las mismas. Sólo son de sillares la fachada principal y los cuatro torreones. El resto de los muros son de tapial. En el proyecto aparece una partida de $1.275 \mathrm{~m}^{2}$ de «limpieza y repaso de paramentos en fachada», que se correspondería con la superficie de las tres fachadas de tapial.

En las fotos de principio de siglo se comprueba que en la fachada principal los sillares aparecían a la vista, con su parte baja y los recercados de los huecos encalados. Las zonas de tapial vistas no parecen en muy buen estado, y el resto estarían ocultas por las edificaciones adosadas o por el terreno.

Al comienzo de un artículo de la Revista Ferias Andaluzas de 1919, un misterioso licenciado X visita el Colegio de Bonifacio Obispo y describe en un cierto tono poético al aspecto exterior del edificio:

Recios son sus muros y tienen sus sillares esas grietas y lacras que el tiempo deja en todo y a la vez la serena majestad de lo viejo... ${ }^{36}$

Durante las obras de acondicionamiento del inmueble para uso universitario ejecutadas en 1994 por el Ayuntamiento de Osuna, dirigidas por el autor de este artículo, todas las fachadas, incluso la principal, estaban revestidas con un tratamiento esgrafiado que simulaba el aparejo del sillar excepto los torreones y contrafuertes. No obstante, este revestimiento no era homogéneo y el de mayor calidad en su ejecución aparecía precisamente en la fachada principal. Incluso en los torreones traseros se había disimulado el llagueado del sillar para que se correspondiera con el revestimiento de la fachada norte. Se desconoce qué parte del revestimiento se realizó en el 27 o si hubo obras posteriores de repaso de las fachadas. En cualquier caso, siempre ha sido tradicional en Osuna la identificación del sillar visto con un cierto prestigio de los inmuebles y, por tanto, de sus propietarios. Quizás por este motivo, el propio Francisco Olid describe erróneamente la construcción como si todas sus fachadas fueran de sillar o piedra:

... los viejos muros se limpiaron de cal que los cubría para que luciera el sillar, y aquellas partes donde la piedra estaba dañada fueron cubiertas con un revestimiento semejante al sillar ${ }^{37}$.

34 Burraco Barrera, M. y Carbajal Navarro, J.A.: Propuesta de Actuación en el Colegio-Universidad de Osuna, I.N.B. Rodríguez Marín, 1982. Archivo de Urbanismo del Ayuntamiento de Osuna, pág. 9. Moreno de Soto, P. y Ruíz Cecilia, J.I.: 2007, pág. 50.

35 Burraco Barrera, M. y Carbajal Navarro, J.A.: Op. Cit. Pág. 9.

${ }^{36}$ Moreno de Soto, P. y Ruiz Cecilia, J.I.: 2007, pág. 46.

${ }^{37}$ Ramírez Olid, J.M.: 1992. Pág. 183. 
Reparaciones en cubiertas

Otra partida importante en el presupuesto, la única que incluye elementos estructurales, es la destinada a reconstrucción de armadura, relativa a la estructura de la cubierta de la nave situada junto al foso y que luego seguiría sufriendo problemas. En la Memoria se señala:

Se propone también la reconstrucción de la armadura de cubierta de la nave o crujía lateral derecha, la que según el reconocimiento practicado se encuentra en mal estado de conservación.

Las armaduras son estructuras de madera que suelen originar empujes horizontales en las cubiertas y, por tanto, problemas en los muros de los edificios. En la planta alta, las cubiertas de las crujías que rodean el patio están actualmente resueltas con cerchas o forjados de hormigón, que posiblemente sustituyeron a las anteriores en las diversas obras de arreglos de tejados realizadas en los años 60 y 70 . No obstante, siguen apareciendo ciertos problemas de empujes del techo en artesa del Paraninfo, que mantiene su cubierta original, y que obligó a disponer en 1945 el atirantado del Torreón suroeste visible en la sala.

Dentro de las obras de restauración de elementos concretos en las cubiertas, se incluyen también los antepechos y las cornisas de la fachada principal, las gárgolas de piedra y el repaso del encuentro entre las cubiertas de las dos primeras crujías resuelto con una canal maestra.

\section{Acabados}

Otro capítulo importante dentro del Proyecto son las solerías, que ascienden casi al 30\% del presupuesto total, proponiéndose:

... la sustitución de la mayor parte de las solerías, pobres y deterioradas, por otras de mármoles o losetas de color con tiras de barro vidriado.

Las solerías, con una superficie en mediciones de unos $2.000 \mathrm{~m}^{2}$, debieron extenderse a la casi totalidad de los espacios del inmueble. Se incluyen en el Presupuesto las siguientes partidas:

- Solería de mármol blanco del país fajeado con mármol rojo, que debe referirse al patio. Sería renovada posteriormente en 1970.

- Mármol blanco fajeado con mármol de color.

- Solería de canto rodado blanco y negro.

- Losas de cemento de color y tiras vidriadas. Debe referirse a la solería hidráulica en damero de la galería de la planta alta del claustro, que se respetó en las obras de 1994 por considerarse característica del edificio.

- Solado con piezas de barro vidriado en cornisa del Patio, que posiblemente nunca se colocaron, puesto que no han llegado hasta nosotros. Lo mismo ocurriría con las tiras de cerámica vidriada previstas en combinación con el resto de las solerías.

El único suelo de madera que ha llegado hasta nosotros es el del Paraninfo, desconociéndose si en el 27 había más estancias en planta alta con esta solución constructiva, aunque en la Memoria solo se habla de sustituir «solerías pobres y deterioradas».

Dentro de los revestimientos también se destinaron varias partidas a los zócalos interiores, definiéndose en la Memoria:

En las galerías que circundan el patio en ambas plantas se proyecta la colocación de zócalos de mármol de color, interrumpidos en la de planta baja por bancos revestidos del mismo material. En las Aulas o Cátedras se colocará un sencillo plinto de azulejos de color adecuado según el de la solería.

En el presupuesto aparecen las partidas siguientes referidas a zócalos, bancos y plintos:

- Zócalo de mármol gris de $50 \mathrm{~cm}$ de altura, que debió ser el que aparecía en la planta baja del claustro en las obras de 1994.

- Mármol gris para los bancos, que estaban previstos para la planta baja del claustro y que quizás nunca se llegaran a ejecutar. ha llegado.

Mármol rojo de $65 \mathrm{~cm}$ de altura. Quizás destinado a la planta alta y que tampoco nos 


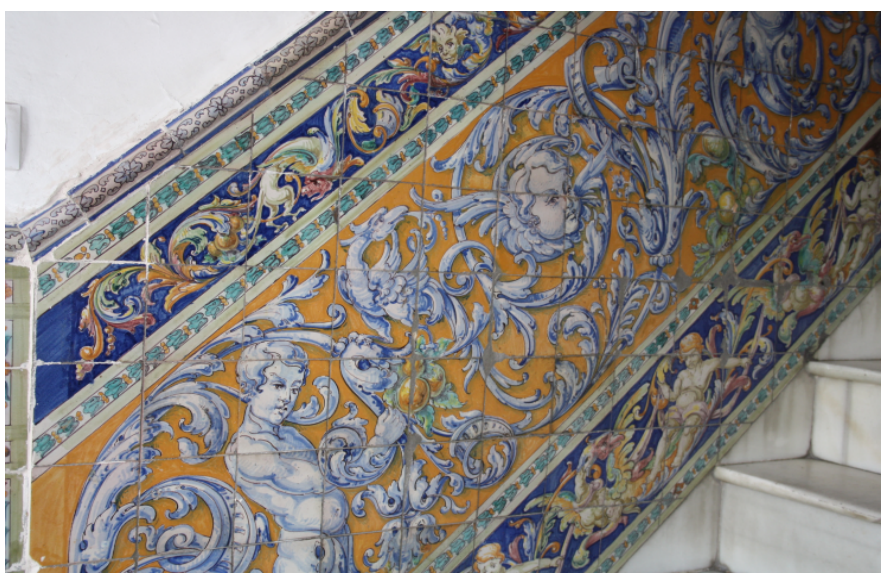

Fig. 9. Revestimiento de escalera en edificio de Paseo de Colón $n^{\circ}$ 12 de Sevilla.

- Plintos de azulejos blancos. Se trataría de los rodapiés para las aulas.

Una zona donde fue intensa la restauración fue la escalera, que si bien no aparece reseñada en la Memoria, sí se incluye en el presupuesto en varias partidas: revestimiento de peldaños con losetas catalanas, tabica vidriada y mamperlanes de caoba; solería con losas catalanas en mesetas; zócalo de cerámica con reflejo oro y dibujo renacimiento y pasamanos con balaustre, solera y cimera de caoba, que sí se corresponde con la escalera actual.

En la escalera actual no aparecen los revestimientos descritos en el presupuesto. Por ejemplo las tabicas son baldosas hidráulicas similares a las de la galería de planta alta, no las plaquetas vidriadas previstas. Tampoco nos ha llegado el «zócalo de cerámica reflejo oro dibujo renacimiento» que, de haberse colocado, hubiera sido similar al que puede observarse en la escalera de acceso a las viviendas del mismo arquitecto en el Paseo de Colón, muy del gusto regionalista de la época (figura 9).

También dentro de la escalera existe una partida para la reparación de yesería en cornisa y bóveda de la escalera principal, que seguramente fue sensiblemente modificada.

Aparece previsto un revestimiento de peldaños «en escalera posterion» que puede referirse o bien a los escalones existentes en la parte trasera del foso o, más probablemente, a alguna salida posterior prevista en el edificio para acceder al campo de deportes.

Además, se destinó una partida concreta al revestimiento con azulejos de los chapiteles de los cuatro torreones. En las fotos antiguas no se aprecia con claridad cómo estaban revestidos anteriormente. La imagen actual de éstos, con el ajedrezado blanco y añil con azulejos vidriados tan característico del edificio, podría ser otra aportación de las obras del 27. La solución se corresponde con el gusto regionalista de la época y la adscripción del arquitecto Pedro Sánchez Núñez a este movimiento, que no llegaría a tener demasiada incidencia en Osuna.

Este contraste estilístico, tan asumido en nuestra percepción del monumento, se refleja en la descripción que del mismo aparece en la página web oficial de la Universidad de Sevilla ${ }^{38}$ :

La sobriedad cromática y constructiva de los paramentos contrasta con los azulejos de las cúpulas de los torreones, que dan un aspecto palaciego al conjunto.

\section{Carpintería de madera, yesería y pintura}

En el capítulo de carpintería de madera se prevé la «reposición de portajes de madera y puertas vidrieras en los huecos existentes y en los de nueva formación, incluyéndose partidas para puertas de faja y tablero, puertas con vidrio corriente y puertas de seguridad». Puertas y ventanas se encuadran en el mismo epígrafe.

38 http://personal.us.es/alporu/historia/univ_osuna.htm (21/01/2015) Respecto al aspecto palaciego ya hemos visto las referencias tipológicas para edificios universitarios en el XVI. 
Fig. 10. Chapitel del torreón revestido de azulejo vidriado.

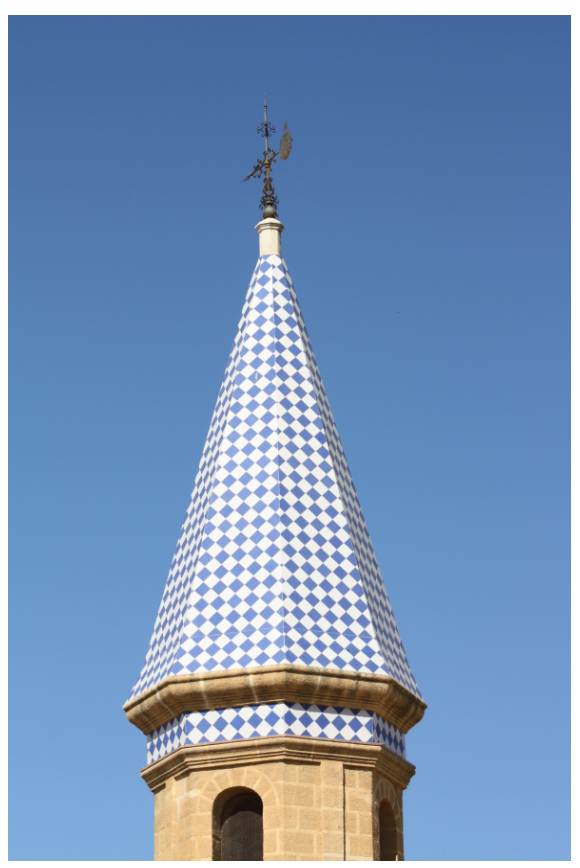

En las aulas se había previsto también la instalación de plataformas de madera para las cátedras, con sus correspondientes balaustradas, que no sabemos si llegaron a colocarse. En una foto de los años 40 del Paraninfo (figura 11) puede observarse la balaustrada sobre la plataforma de madera, con un diseño similar a los balaustres existentes en la escalera principal.

También se prevé en la Memoria la «reparación y pintura de techos y artesonados de madera o de yeserías».

En el presupuesto se incluyeron cielorrasos (falsos techos) con molduras y enlistonado, que debían destinarse a alguna zona donde estaría en mal estado en planta alta, así como varias partidas para pinturas:

- Pintura en techos de madera, que debían ser la mayor parte de las estancias del edificio.

- Pintura policromada y dorada en techos, que deben referirse al techo de la Capilla y vestíbulo.

- al claustro e interior de las estancias.

Instalaciones

En la línea de adaptar el inmueble a las necesidades de salubridad, se prevén en la Memoria:

... obras de saneamiento que consistirán en la instalación de un grupo de motor-bomba para elevación de las aguas del aljibe situado en el patio, construcción del depósito y tuberías de distribución e instalación de los correspondientes e imprescindibles servicios sanitarios para Profesores y Alumnos.

En el presupuesto aparecen partidas genéricas destinadas a retretes completos para profesores y alumnos, instalación de aguas y grupos de pozos sépticos y de oxidación.

Hay que tener en cuenta que el municipio de Osuna ha tenido problemas de abastecimiento de agua corriente hasta los años 60 del siglo XX, utilizándose sólo la procedente de los diversos manantiales de la localidad. La Universidad tendría que esperar hasta los proyectos del Ministerio de Educación de los años 80 para que se resolviera su acometida de aguas, siendo necesaria la utilización de un grupo de bombeo, por no existir suficiente desnivel entre el edificio y los depósitos generales de la ciudad. Anteriormente, se utilizaba el agua no potable del gran aljibe situado en el patio, ahora destinado a depósito para la instalación contra incendio. 


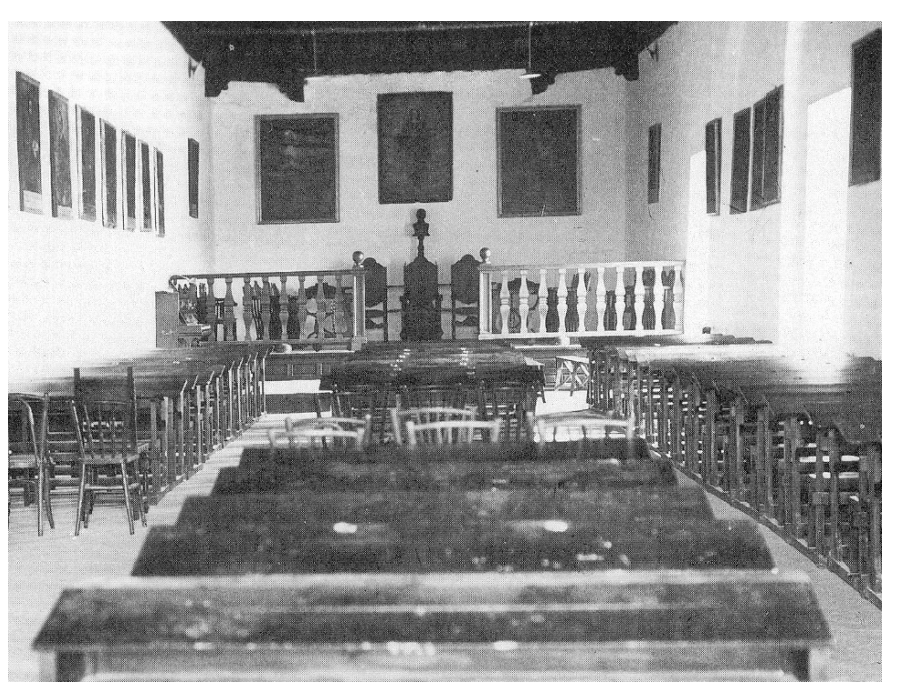

Fig.11. El Paraninfo en los años 40.

En cuanto al saneamiento, estuvo resuelto con fosas sépticas hasta los años 90 del siglo pasado, en que se conectó a la red de alcantarillado de Osuna, mediante un nuevo colector hasta la Cuesta de Marruecos.

Continuando con las instalaciones, en el presupuesto aparecen partidas genéricas para estas instalaciones de luz eléctrica y pararrayos, que se desmontaron durante las obras de 1994. En el Archivo Municipal ${ }^{39}$ se conserva un presupuesto de enero de 1928 dirigido a Sánchez Núñez para instalar los pararrayos, de un tal Joseph Parfonry, industrial belga especializado con oficina en Sevilla. Además de una extensa memoria para demostrar la validez científica de su instalación, aparece un croquis muy simplificado de las cubiertas que no se corresponde en absoluto con la realidad. Lamentablemente, es el único plano que aparece en el expediente del proyecto de las obras de 1927.

\section{Obras en el entorno}

En la Memoria se señala también que:

... como anexo a este Proyecto se está ultimando el estudio de la Urbanización de los alrededores y de las vías de acceso al edificio el cual será presentado a la mayor brevedad a la consideración del Excmo. Ayuntamiento, haciéndolo hoy solo de este con objeto de no demorar el comienzo de las obras.

Desconocemos si se llegó a redactar el referido Anexo, pero del texto se deduce la intención del arquitecto de participar en el diseño de las obras exteriores. Sí tenemos ciertos datos sobre las que efectivamente llegaron a realizarse.

En febrero de 1928 el Alcalde hizo las gestiones con el Arzobispado para la cesión del antiguo cementerio para pobres, cerrado desde 1846, tras la instalación del actual en el Camino de Écija. El Ayuntamiento asumió los costes de la demolición del cerramiento, obteniendo el Arzobispado el beneficio de la venta de los sillares que lo formaban para continuar las obras de reconstrucción de la Colegiata ${ }^{40}$. Esto permitió la configuración actual de la explanada que, a pesar de no haberse pavimentado hasta fechas recientes, ha funcionado como espacio de articulación entre los dos monumentos.

En cuanto a los accesos urbanos a la Universidad, el único existente era la estrecha y empinada la cuesta de San Antón, que en el plano de 1895 discurría desde la Plaza Mayor hasta la misma Universidad, rodeando un solar hoy inexistente que ocupaba la Plaza de la Encarnación. Esta dificultad de accesos a la zona alta pudo ser uno de los motivos que llevó al abandono del recinto amurallado.

\footnotetext{
${ }^{39}$ A.M.O. Obras y Urbanismo. Planos y Proyectos. Proyecto de Reforma del Instituto (1927-1952) Sig. 202.

${ }^{40}$ Ramírez Olid, J.M.: 1999, pág. 592.
} 
Para mejorar la accesibilidad y el acceso de vehículos tanto a la Universidad como a la Colegiata, se convirtió en carretera el camino de Buenavista, que discurría desde el final de la calle Granada y San Cristóbal hasta el callejón de los Seminaristas, y finalizar frente a una casilla de consumos situada junto al torreón suroeste de la Universidad.

Al estar situado por encima de la población, este viario de borde nunca llegó a convertirse en una calle urbana consolidada. En el plano de 1895 carecía de nombre y, hoy en día, aún no existe ningún inmueble cuya fachada principal se abra al mismo. De hecho, siempre se ha denominado camino o carretera pero nunca calle o paseo. Además, siguen sin resolverse sus bordes desde el punto de vista urbanístico. A pesar de su nombre, desde el mismo lo que se divisan son los dos grandes vacíos urbanos situados junto al callejón de las Descalzas y a la cuesta de Marruecos.

En el otro extremo del Camino de Buenavista, se llegaría en enero de 1929 a un acuerdo con el Arzobispado para el derribo de la ermita de San Sebastián, que amenazaba derrumbarse sobre los transeúntes ${ }^{41}$. Estaba situada en la parte alta de la calle Granada, en su encuentro con la calle San Cristóbal, con lo que se consiguió una mayor amplitud en la confluencia de ambas calles. Aparece reflejada en los planos de Osuna de finales del XIX, con lo que podemos deducir que se situaría a la altura del número 122 de la calle Granada, en el margen derecho. Al parecer, un arquillo la enlazaba con la fachada de la última casa de la calle San Cristóbal, a modo de puerta hacia el campo.

Dentro de las actuaciones sobre el viario realizadas en esos años, también se pavimentaron la escalinata de Cuesta de Marruecos y la propia calle Granada.

\section{Conclusiones}

La afirmación de que las obras de 1927 ocasionaron un cambio radical en la imagen del edificio se relaciona con el impacto que debió suponer el derribo de las construcciones adosadas y la creación de tres fachadas nuevas, con una disposición de huecos en retícula regular, en una aproximación a un supuesto modelo ideal de monumento aislado renacentista. A esta nueva imagen contribuyeron también la apertura del foso, la creación de la plataforma donde se asienta y la configuración de la explanada de la Colegiata como espacio libre. Estas obras, que hay que encuadrar dentro de una época y unas teorías decimonónicas de actuación sobre los monumentos, han influido en la línea de actuaciones posteriores sobre el edificio y su entorno.

En 1927, y durante todo el historicismo, las referencias históricas eran utilizadas con libertad, considerándose los elementos de la arquitectura de otras épocas como disponibles para los proyectos de nueva planta. Como ejemplo, el propio Pedro Sánchez en el Pabellón de Castilla la Vieja o en sus fases estilísticas neomudéjar o neobarroca. En esta línea se explica la incorporación de elementos regionalistas a una edificación del XVI, como los azulejos de los chapiteles de los torreones, o el zócalo «tipo renacimiento» previsto para la escalera. Con el eclecticismo, la mezcla de estilos no estaba proscrita. De hecho, los azulejos parecen haberse integrado sin dificultad, o al menos, han sido asumidos con el paso del tiempo, llegando a formar parte de la imagen característica del edificio.

Pero el principal impacto en el cambio de imagen de la edificación fue sin duda el derribo de los cuerpos adosados y los cambios en el entorno. La actuación se encuadra en un período donde, desde finales del XIX y con las leyes de ensanche de las poblaciones, no se dudaba al trazar nuevos viarios dentro de los cascos históricos, derribando las construcciones antiguas afectadas. El propio Sánchez Núñez redactaría un plan que incluía varias de estas operaciones de ensanche interior para Sevilla.

Las teorías de la restauración surgidas en el XIX, favorecieron el aislamiento del monumento de las impurezas que, con el paso del tiempo, se les había ido adosando. Todavía en los años 20, Torres Balbás publicaba un artículo con un título explícito: "Aislar monumentos, enfermedad de moda". En esta línea, el proyecto supone el derribo de los

${ }^{41}$ A.M.O. Acta de Pleno de 3/1/1929, folio 187. 
restos de dos edificaciones del XVI, creando tres nuevas fachadas en el edificio original. No obstante, la actuación tuvo varios aspectos positivos que merecen ser destacados:

- La supresión del cementerio y su conversión en un espacio público que sirve de articulación entre la Colegiata y la Universidad, en su principal acceso.

- La mejora de la accesibilidad a través del camino de Buenavista, que luego tendría su continuidad en los años 60 con el Paseo de la Universidad y la Cuesta de los Cipreses.

- La consolidación del uso educativo, que perduraría hasta 1992 como Instituto de Enseñanza Media y ha permitido la recuperación de la Universidad de Osuna.

Las obras tuvieron un efecto secundario aún más importante: iniciaron un proceso irreversible, porque no es posible dar marcha atrás y reconstruir los edificios derribados, incluso en el supuesto de que tuviéramos datos suficientes sobre los mismos ${ }^{42}$. En este sentido, la actuación de 1927 sobre un edificio histórico como la Universidad de Osuna ha pasado a formar parte también de la propia historia del mismo.

42 El artículo 20.4 de la vigente Ley 14/2007 de Patrimonio Histórico de Andalucía señala: «En el caso de bienes inmuebles, las actuaciones a que se refiere el apartado 3 evitarán los intentos de reconstrucción, salvo cuando en su reposición se utilicen algunas partes originales de los mismos o se cuente con la precisa información documental y pueda probarse su autenticidad. Si se añadiesen materiales o partes indispensables, las adiciones deberán ser reconocibles y evitar las confusiones miméticas.» 
Bibliografía

Burraco Barrera, M. y Carbajal Navarro, J.A..: Propuesta de Actuación en el Colegio-Universidad de Osuna, I.N.B. Rodríguez, Marín. Archivo de Urbanismo del Ayuntamiento de Osuna. (1982).

Ledesma Gámez, F.: Las murallas de Osuna. Sevilla, Diputación de Sevilla, (2003).

Ledesma Gámez, F., ed.: Catálogo de la exposición: Del arca de las tres llaves al fichero digital. Quinientos años del Archivo de Osuna. Sevilla, (2009).

Morales, A. J. y otros: Guía artística de Sevilla y su provincia. Sevilla, Diputación Provincial, (1989).

Moreno de Soto, P. y Ruíz Cecilia, J. I.: "El Antiguo Edificio de la Universidad de Osuna y su complejo docente. Nuevas perspectivas". Cuadernos de los Amigos de los Museos de Osuna. $\mathrm{N}^{\circ}$ 9. (2007).

Nieto, V. Morales, A. J. Checa, F.: Arquitectura del Renacimiento en España, 1488-1599. Madrid, Cátedra, (1989).

Ramírez Olid, J. M.: “La enseñanza secundaria en Osuna 1847-1927” en Hijo de entendimiento. Homenaje a don Alfredo Malo, catedrático en Osuna. Osuna, Ayuntamiento de Osuna, (1992).

Ramírez Olid, J. M.: Osuna durante la restauración (1875-1931). Osuna, Ayuntamiento de Osuna, (1999).

Villar Movellán, Alberto: Arquitectura del Regionalismo en Sevilla (1900-1935). Sevilla, Diputación de Sevilla, (1979).

\section{Webgrafía}

personal.us.es/alporu/historia/univ_osuna.htm (19/04/2016) 